\title{
LARYNGOLOGY
}

\section{Voice aspects in sulcus coexisting with benign lesions of the vocal folds}

\author{
Caratteristiche della voce in pazienti con sulcus e lesioni benigne delle corde vocali \\ Beata Miaśkiewicz'1, Aleksandra Panasiewicz¹, Elżbieta Gos², Agata Szkiełkowska1', Piotr H. Skarżyński², Elżbieta Włodarczyk² \\ ${ }^{1}$ Audiology and Phoniatrics Clinic, Institute of Physiology and Pathology of Hearing, Kajetany, Warsaw, Poland; ${ }^{2}$ Teleaudiology and \\ Screening Department, Institute of Physiology and Pathology of Hearing, Kajetany, Warsaw, Poland
}

\begin{abstract}
SUMMARY
The purpose of this study was to measure the clinical profile of patients with sulcus who had concomitant benign lesions such as polyp, oedema, cyst, nodules, or fibrous mass of the vocal fold. We reviewed the medical charts of 38 patients who had a diagnosis of sulcus type 2 or 3 (according to Ford). The patients were classified into two groups. The study group consisted of 16 subjects who had sulcus and associated benign lesion; 22 patients diagnosed with sulcus alone were enrolled in a control group. We analysed psychosocial (Voice Handicap Index-30), auditory-perceptual (GRBAS), acoustic measures and videostroboscopic images. In the study group, the mean VHI-30 scores of all subscales ranged from moderate to severe handicap. The difference between groups was significant on the emotional $(\mathrm{p}=0.004)$ and physical $(\mathrm{p}=0.007)$ subscales. On GRBAS scale, the majority of patients from both groups exhibited mild hoarseness, breathiness, asthenic or strained voice, although roughness was more frequently rated moderate; the differences between groups were not statistically significant. The most abnormally increased values were achieved for amplitude values of acoustic parameters, but significant difference between groups was found in Soft Phonation Index only $(p=0.049)$. Concerning glottal closure, the most frequent finding was irregular chink in the study group, and spindle glottic chink in controls; we found significant differences between groups $(\mathrm{p}=0.004)$. In both series of patients, the most frequent abnormal findings were moderately diminished amplitude and moderately restricted mucosal wave, with no significant difference between groups. Patients with sulcus and coexisting benign lesions were more handicapped on the emotional and physical subscales of VHI-30. The most characteristic shape of the glottal gap was irregular chink in the study group, and spindle chink in the control group. Acoustic evaluation of voice showed that the most severe disturbances affected amplitude parameters. The clinical characteristics indicated that the presence of sulcus primarily determines the quality of voice, and that additional benign pathologies do not drastically affect further voice deterioration. The coexistence of secondary benign vocal fold lesions aggravates the difficulties in making a preoperative diagnosis of sulcus. It is important to clinically suspect the possibility of coexistent sulcus to plan the correct treatment and obtain better voice outcomes.
\end{abstract}

KEY WORDS: larynx, laryngoscopy, polyps, vocal folds, hoarseness

\section{RIASSUNTO}

Lo scopo di questo lavoro è valutare il profilo clinico dei pazienti con sulcus ed affetti contestualmente da lesioni benigne come polipi, edema, cisti, noduli o fibromi delle corde vocali. Abbiamo analizzato le cartelle cliniche di 38 pazienti con diagnosi di sulcus di tipo 2 o 3 (secondo FORD). I pazienti sono stati suddivisi in due gruppi. Il gruppo di studio è composto da 16 pazienti con sulcus e lesioni benigne cordali; il gruppo di controllo è costituito da 22 pazienti con diagnosi di sulcus senza altre lesioni cordali associate. Abbiamo valutato il Voice Handicap Index-30, GRBAS, misurazione acustica ed immagini videostroboscopiche. Nel gruppo di studio i punteggi medi del VHI-30 sono compresi in un range di handicap dal moderato al severo. Sono emerse delle differenze statisticamente significative nei due gruppi nelle valutazioni emozionali e fisiche (rispettivamente $p=0,004$ e $p=0,007$ ). Sulla scala GRBAS, la maggior parte dei pazienti di entrambi i gruppi ha mostrato raucedine di grado lieve, respiro affannoso, voce astenica o tesa, sebbene l'irregolarità fosse risultata più frequentemente di grado moderato, con differenze statisticamente non significative nei due
Received: November 21, 2019

Accepted: March 22, 2020

\section{Correspondence}

Beata Miaśkiewicz

Audiology and Phoniatrics Clinic, Institute of Physiology and Pathology of Hearing, Mokra 17 Str., Kajetany, 05-830 Nadarzyn, Warsaw, Poland Tel. +482235603 51. Fax +48223560386 E-mail: b.miaskiewicz@ifps.org.pl

\section{Funding}

The work was done in the Audiology and Phoniatrics Clinic and Otorhinolaryngology Surgery Clinic of the Institute of Physiology and Pathology of Hearing, Warsaw, Poland. The Institute of Physiology and Pathology of Hearing covered all expenses incurred during the study.

\section{Conflict of interest}

The Authors declare no conflict of interest.

How to cite this article: Miaśkiewicz B, Panasiewicz A, Gos E, et al. Voice aspects in sulcus coexisting with benign lesions of the vocal folds. Acta Otorhinolaryngol Ital 2020;40:262-269. https://doi. org/10.14639/0392-100X-N0555

(C) Società Italiana di Otorinolaringoiatria e Chirurgia Cervico-Facciale

\section{(c) $(1) \Theta$}

This is an open access article distributed in accordance with the CC-BY-NC-ND (Creative Commons Attribution-NonCommercial-NoDerivatives 4.0 International) license. The article can be used by giving appropriate credit and mentioning the license, but only for non-commercial purposes and only in the original version. For further information: https:// creativecommons.org/licenses/by-nc-nd/4.0/deed.en 
gruppi. L'alterazione più evidente dei valori è risultata essere quella a carico dell'ampiezza dei parametric acustici, tuttavia l'unica differenza statisticamente significativa è risultata a carico del Soft Phonation Index ( $p=0,049)$. Per quanto concerne la chiusura glottica, l'alterazione più frequente nel gruppo di studio è stata una rima glottica irregolare mentre nel gruppo dei controlli, una rima glottica fusiforme, ( $p=0,004)$. In entrambe le serie di pazienti le alterazioni più frequenti sono state l'ampiezza moderatamente ridotta e l'onda della mucosa moderatamente limitata, ma non abbiamo riscontrato differenze significative tra i due gruppi.

Le caratteristiche cliniche indicano che la presenza di solco influisce in manieradeterminante sulla qualità della voce mentre le ulteriori patologie benigne associate al sulcus influiscono solo parzialmente sulla disfonia. La coesistenza di lesioni secondarie benigne delle corde vocali rende più difficile formulare una diagnosi preoperatoria di sulcus. ̇̀ importante sospettare clinicamente la possibilità di un sulcus coesistente per pianificare il giusto trattamento al fine di ottenere un migliore risultato vocale.

PAROLE CHIAVE: laringe, laringoscopia, polipi, corde vocali, raucedine

\section{Introduction}

Sulcus is a laryngeal condition linked to a clinically inhomogeneous defect of the epithelium covering the vocal folds in which there is a structural malformation, ranging from minor invagination to a deep focal pouch.

The classifications of sulci used today were introduced by Bouchayer and Cornut ${ }^{1}$, and Ford ${ }^{2}$. Bouchayer and Cornut proposed to distinguish sulcus vergeture (which Ford named sulcus type 2) and sulcus vocalis (the open epidermoid cyst which Ford named sulcus type 3) as two distinct anatomical phenomena ${ }^{1}$. Vergeture is characterised as an atrophic groove under the free edge of the vocal fold that extends close to the vocal ligament. Sulcus vocalis refers to a pocket lined with a thick epithelium extending into the Reinke's space as deep as the vocal ligament or muscle ${ }^{1}$. It is characterised by tissue loss throughout the entire lamina propria ${ }^{3}$. Ford and colleagues ${ }^{2}$ extended this classification to account for variability in clinical appearance. In addition types 2 and 3, they distinguished type 1 as involving an asymptomatic subtle depression along the free edge with normal or minimally altered mucosal wave and an intact layered structure of the lamina propria.

To date, there is no consensus regarding the aetiology of sulcus. Arguments for congenital origin link sulcus to epidermoid cyst and mucosal bridge of the vocal fold, representing the fourth and sixth branchial arch anomalies ${ }^{1,4}$. Keratin debris (fibrous mass) embedded deep within the sulcus or a concomitant scar are not unusual intraoperative findings ${ }^{5,6}$. Nakayama and colleagues found a high incidence $(48 \%)$ of sulcus deformities in pathological examinations for laryngeal cancer, and suggested an acquired origin resulting from local trauma and/or chronic inflammation ${ }^{7}$. A mechanism similar to the development of middle ear cholesteatoma was considered by Lee et al. ${ }^{4}$.

Sulcus leads to vocal fold stiffness and deformity of the medial edge, resulting in glottal insufficiency; consequently, patients very often present supra-glottal and glottal hyperactivity or even a severe compression that may result in development of other concomitant benign lesions, such as polyp, oedema, or vocal fold nodules. The incidence of concomitant lesions in sulcus cases is reported to be $6.4 \%$ to $64 \%^{8-14}$. The presence of such benign lesions can reveal the underlying condition (sulcus) and may influence voice quality. Proper diagnosis based on thorough clinical examination allows for specific treatment and rehabilitation, and also provides reliable prognosis for voice improvement. There is only a handful of studies related to specific voice characteristics of patients with sulcus and coexistent benign lesions of the vocal folds. The goal of the present study was to analyse the clinical characteristics of patients with sulcus and concomitant benign lesions; the analysis considered psycho-social handicap, auditory-perceptual ratings, acoustic measurements and vibratory patterns.

\section{Materials and methods}

We carried out a retrospective study based on charts of 38 patients with diagnosed sulcus (with and without coexistent benign lesions) who were treated surgically at the Institute of Physiology and Pathology of Hearing between 2011 and 2017. The diagnosis and classification of sulcus were made by a laryngologist following stroboscopic examination. Diagnoses were confirmed or revised by the same laryngologist during subsequent direct microlaryngoscopy. Patients undergoing intervention for a benign lesion of the vocal fold e.g. polyp, nodules, oedema, in whom sulcus was discovered during palpation with a blunt micro-instrument were included in this study based on the intraoperative diagnosis. The final inclusion criterion in this study was the presence of sulcus (with and without concomitant lesions) during surgery.

The exclusion criteria were: sulcus suspected during videolaryngostroboscopy but not confirmed in microlaryngoscopy, incomplete medical charts and prior laryngeal surgeries.

Patients were classified into two groups. The study group consisted of 16 subjects who had sulcus and associated benign lesions. Twenty-two patients with isolated sulcus were included in the control group. 
The study group consisted of 13 women and 3 men aged from 28 to 66 years $(\mathrm{M}=39.62 ; \mathrm{SD}=10.171)$. There were 7 patients with type 2 sulcus and 9 with type 3 . Eight patients were diagnosed with unilateral sulcus and 8 with bilateral sulci. In cases of bilateral sulci they were of the same type on both vocal folds. In 7 subjects sulcus presented with concomitant vocal fold fibrous mass, while a polyp coexisted in 3 patients, mucosal bridge in 3 , Reinke oedema in 2 , vocal nodules in 1 , epidermoid cyst in 1 , scar in 1 and presbylarynx in 1 patient. Additionally, 3 patients had two lesions that simultaneously presented a fibrous mass and mucosal bridge, fibrous mass and polyp and vocal nodules with mucosal bridge. In 10 cases the concomitant lesions were found unilaterally (on the same vocal fold as the sulcus) and in 6 subjects bilaterally.

The control group consisted of 22 subjects diagnosed with sulcus alone: 11 women and 11 men aged from 22 to 70 years $(M=46.05 ; S D=12.96)$. There were unilateral sulci in 6 patients and bilateral ones in 16. Most patients presented with type 2 sulcus ( 15 cases) or type 3 sulcus ( 7 cases). In cases of bilateral sulci, there was the same type of sulcus on both vocal folds.

The complaints driving diagnostic procedures and conservative or surgical treatment involved: hoarseness, diminished voice intensity and range of voice, vocal fatigue, and strained, breathy or unstable voice. Prior to surgery, $52 \%$ of patients had undergone speech therapy without satisfactory voice improvement. The remaining $48 \%$ were unable to attend preoperative therapy sessions due to a considerable distance from their home or lack of time.

Patient evaluation included psychosocial, auditoryperceptual and acoustic assessments, as well as laryngovideostroboscopy (LVS).

The Voice Handicap Index questionnaire (VHI-30) was administered to evaluate self-perception of voice ${ }^{15}$. The VHI-30 total score (VHI-T) and its components, emotional (VHI-E), physical (VHI-P) and functional (VHI-F) subscale scores, were all calculated.

An auditory - perceptual evaluation of voice was carried out with the GRBAS scale ${ }^{16}$ in which a clinician estimates the grade of hoarseness $(\mathrm{G})$, roughness $(\mathrm{R})$, breathiness (B), asthenia (A) and strain in the voice (S) on a scale from 0 to 3 ( 0 , normal; 1 , mild; 2 , moderate; 3 , severe). Ratings, based on sustained phonation and a short speech sample, were made by a senior laryngologist - phoniatrist (BM) upon initial clinical presentation. The same researcher then retrospectively performed blinded evaluation of the recorded voice samples.

An objective acoustic voice analysis was performed with a Computerised Speech Lab (CSL) 4,500 external module from Kay Elemetrics Corporation (Lincoln Park NJ).
All voices were recorded with an ECM 800 microphone (Behringer) positioned approximately $15 \mathrm{~cm}$ away from the mouth at an angle of $45^{\circ}$ to reduce airflow effects. Analysis of a voice sample recorded at a sample rate of $25 \mathrm{kHz}$ was done using the Multidimensional Voice Program software (MDVP 5105 version 2.7.0). Three samples of the sustained vowel "a" in modal voice were used for analysis; only the middle portion of the uttered vowel was used (min. $0.6 \mathrm{sec}$ ), avoiding onset and offset effects ${ }^{17-19}$. The following acoustic parameters were calculated: average fundamental frequency (F0), frequency variations (\% Jitter; Relative Average Perturbation, RAP; Pitch Perturbation Quotient, PPQ; Smoothed Pitch Perturbation Quotient, sPPQ; Fundamental Frequency Coefficient Variation, vF0), amplitude variations (\% Shimmer; Amplitude Perturbation Quotient, APQ; Smoothed Amplitude Perturbation Quotient, sAPQ; Peakto-Peak Amplitude Coefficient of Variation, vAm), and noise-related parameters (Noise to Harmonic Ratio, NHR; Soft Phonation Index, SPI).

To analyse the acoustic characteristics of patients with sulcus and coexisting benign lesions, we used the normative thresholds as proposed by Delijsky ${ }^{20}$, as well as the norms provided by Kay Elemetrics Corporation which refer to adults in the general population ${ }^{21}$. For each parameter, we determined a cut-off point separating the patients into two groups: one with low values of the given parameter (lower than the normative value) and another with high values (above the norm).

Laryngovideostroboscopy (LVS) was performed with a $70^{\circ}$ rigid laryngoscope (EndoStrob DX Xion 327, GmbH, Germany), while glottal closure and vibration characteristics of the vocal folds were assessed subjectively.

The pattern of glottal closure was rated on a 6-point scale according to Lim's proposal ${ }^{22}$ as follows: 0, complete closure; 1, anterior glottic chink; 2, posterior chink; 3, spindle glottic chink; 4, irregular glottic chink; 5, incomplete glottic closure (no glottal contact).

Amplitude and mucosal wave were evaluated with a 4-point scale. Amplitude was rated as: 0, normal; 1, mildly diminished; 2 , moderately diminished; 3 , severely diminished; and mucosal wave: 0 , normal; 1 , mildly restricted; 2 , moderately restricted; 3 , completely lacking. All stroboscopic videos were evaluated preoperatively, and the recordings were retrospectively assessed in an anonymous fashion by the same senior laryngologistphoniatrist who performed auditory-perceptual ratings.

Operations were performed under general anaesthesia with suspended microlaryngoscopy and endotracheal intubation. In the first step of the procedure, the vocal folds were inspected under magnification with an operating microscope and palpated with a blunt instrument to assess 
the type of pathology or search for any other unexpected lesions.

If the coexistent benign lesion was present, it was removed during the same surgical procedure. The surgical technique for sulcus was based on the concept by Bouchayer and Cornut with Remacle's modification ${ }^{1,8,23}$.

In cases of coexisted vocal nodules and polyp the medial microflap technique was applied, whereas epidermoid cyst, Reinke's oedema, scar and fibrous mass were treated by the lateral microflap technique.

If there was a significant vocal fold atrophy, injection laryngoplasty was performed during the same operation. We used two injectable materials: hyaluronic acid (HA; Surgiderm 24 XP, Allergan) and calcium hydroxylapatite (CaHa; Radiesse Voice Implant, Merck). Postsurgical voice therapy was mandatory in all subjects and involved one session a week for 2-5 months, or patients were referred to hospitalisation with voice rehabilitation.

\section{Statistical analysis}

The normality assumption of quantitative variables (the VHI scores and acoustic parameters) was examined by the ShapiroWilk test. Afterwards, a two-sample t-test or the MannWhitney U test was conducted. A chi-square test was used to test differences between the study group and control group in terms of categorical variables (the results for GRBAS and for assessment of glottal closure, amplitude and mucosal wave). Data analysis was done using IBM SPSS Statistics v. 24.

\section{Results}

\section{Voice Handicap Index}

Summary statistics for the VHI-30 subscale scores and total score for patients from the study group are presented in Table I. According to the criteria described by Jacobson et al. ${ }^{11}$ the mean scores of all subscales ranged from moderate (functional) to severe (physical, emotional) handicap, and the total score was moderate.

Figure 1 compares the VHI-30 scores between patients from the study group and controls (the sulcus group).

Table I. Descriptive statistics for VHI-30 scores (for patients with benign lesions $(n=16)$.

\begin{tabular}{cccccc} 
& Min & Max & M & SD & Me \\
VHI-F & 0 & 26 & 12.69 & 8.48 & 11.00 \\
VHI-E & 2 & 40 & 17.38 & 11.63 & 16.00 \\
VHI-P & 9 & 36 & 23.88 & 8.91 & 26.50 \\
VHI-T & 15 & 99 & 53.00 & 25.66 & 44.50 \\
\hline
\end{tabular}

Min: minimum; Max: maximum; M: mean; SD: standard deviation; Me: median; VHI-30 (F): functional subscale; VHI-30 (E): emotional subscale; VHI-30 (P): physical subscale; VHI-30 (T): total score.

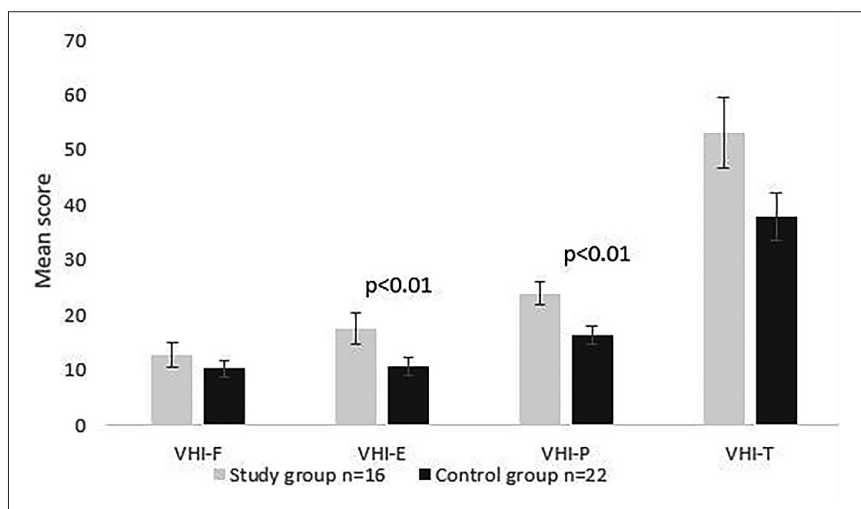

VHI-30 (F): functional subscale; VHI-30 (E): emotional subscale; VHI-30 (P): physical subscale; VHI-30 (T): total score. Bars are mean values; error bars are standard errors.

Figure 1. Comparison of VHI- 30 scores between study group and controls.

The difference between groups in VHI scores was significant for the emotional $(\mathrm{p}=0.004)$ and physical $(\mathrm{p}=0.007)$ subscales, indicating that patients with concomitant benign lesions were more handicapped in both these domains than patients without coexisting benign lesions. On the functional subscale, the groups did not differ ( $\mathrm{p}=0.330$ ). For the global VHI-30 score the $\mathrm{p}$ value was 0.05 , and the $95 \%$ confidence interval of the difference was $[-0.015 ; 30.615]$ (it spanned 0 ), so the difference cannot be considered significant.

\section{Perceptual evaluation (GRBAS)}

Data on GRBAS parameters are presented in Table II, which shows the number of subjects and percentages (in brackets). The majority of patients in the study group presented with a mild grade of hoarseness (69\%), whereas $31 \%$ had a normal voice in the perceptual assessment. Concerning the $\mathrm{R}$ parameter, most patients had a moderate $(50 \%)$ or mild (37.5\%) grade of roughness. Breathiness appeared mostly mild $(62.5 \%)$, as did strained voice $(69 \%)$. Asthenia was present in $56 \%$ of cases, and was mild.

Comparison of GRBAS indices showed similar values in both groups. For all GRBAS domains, the differences between the study group and controls were not significant $(\mathrm{p}>0.05)$.

\section{Acoustic assessment}

The percentage of high and low values for MDVP is shown in Table III. The values for frequency were above the norm in most individuals in the study group. For vF0, $93.8 \%$ of subjects were above the norm.

High values of amplitude parameters were also observed in the majority of patients, especially for vAm (100\%) and Shim (93.8\%). Elevated values of SPI (37.5\%) and NHR (18.2\%) were less commonly found. 
Table II. Comparison of GRBAS parameters for study group $(n=16)$ and control group $(n=22)$.

\begin{tabular}{|c|c|c|c|c|c|}
\hline \multicolumn{6}{|c|}{ Grade } \\
\hline & Normal voice (0) & Mild (1) & Moderate (2) & Severe (3) & \\
\hline Study group & $5(31 \%)$ & $11(69 \%)$ & 0 & 0 & $\chi^{2}=1.27 ; p=0.530$ \\
\hline \multicolumn{6}{|c|}{ Roughness } \\
\hline & Normal voice $(0)$ & Mild (1) & Moderate (2) & Severe (3) & \\
\hline \multicolumn{6}{|c|}{ Breathiness } \\
\hline & Normal voice (0) & Mild (1) & Moderate (2) & Severe (3) & \\
\hline Study group & $4(25 \%)$ & $10(62.5 \%)$ & $2(12.5 \%)$ & 0 & $\chi^{2}=0.17 ; p=0.919$ \\
\hline Control group & $5(23 \%)$ & $15(68 \%)$ & $2(9 \%)$ & 0 & \\
\hline Control group & $8(36 \%)$ & $14(64 \%)$ & 0 & 0 & \\
\hline \multicolumn{6}{|c|}{ Strain } \\
\hline & Normal voice (0) & Mild (1) & Moderate (2) & Severe (3) & \\
\hline Study group & $2(12 \%)$ & $11(69 \%)$ & 3 (19 \%) & 0 & $\chi^{2}=1.60 ; p=0.660$ \\
\hline Control group & $2(9 \%)$ & $14(64 \%)$ & $4(18 \%)$ & $2(9 \%)$ & \\
\hline
\end{tabular}

Table III. Percentage of patients in the study group $(n=16)$ having high or low MDVP parameters. Abbreviations as in Materials and methods.

\begin{tabular}{lcc} 
& Below norm (\%) & Above norm (\%) \\
Jitt & 31.2 & 68.8 \\
RAP & 31.2 & 68.8 \\
PPQ & 43.8 & 56.2 \\
SPPQ & 37.5 & 62.5 \\
vFO & 6.2 & 93.8 \\
Shim & 6.2 & 93.8 \\
APQ & 25.0 & 75.0 \\
SAPQ & 25.0 & 75.0 \\
VAm & 0.0 & 100.0 \\
NHR & 81.3 & 18.2 \\
SPI & 62.5 & 37.5 \\
\hline
\end{tabular}

Table IV compares the values of the voice parameters in the study group with those in the control group. The analysis showed that, for the SPI parameter, there was a significant difference between groups with the mean value being lower in patients with sulcus and coexisting benign lesions $(\mathrm{p}=0.049)$. The vAm was also elevated, but failed to reach statistical significance $(p=0.067)$. For the remaining parameters, no significant changes were observed between groups.

The percentages of high and low MDVP values were compared between groups (patients with sulcus benign
Table IV. Comparison of MDVP parameters. Abbreviations as in Materials and methods.

\begin{tabular}{lcccccc} 
& \multicolumn{2}{c}{$\begin{array}{c}\text { Study group } \\
\mathbf{n}=16\end{array}$} & \multicolumn{2}{c}{$\begin{array}{c}\text { Control group } \\
\mathbf{n}=22\end{array}$} & $\begin{array}{c}\text { Test } \\
\text { statistic }\end{array}$ & P-value \\
& $\mathbf{M}$ & SD & $\mathbf{M}$ & SD & & \\
F0 & 202.29 & 64.87 & 195.38 & 41.64 & $\mathrm{t}=0.40$ & 0.692 \\
Jitt & 1.98 & 1.21 & 1.71 & 1.15 & $\mathrm{U}=144.00$ & 0.344 \\
RAP & 1.17 & 0.71 & 1.02 & 0.68 & $\mathrm{U}=145.00$ & 0.359 \\
PPQ & 1.21 & 0.76 & 1.00 & 0.70 & $\mathrm{U}=134.50$ & 0.220 \\
SPPQ & 1.54 & 0.91 & 1.27 & 0.64 & $\mathrm{U}=139.50$ & 0.280 \\
vF0 & 3.55 & 2.79 & 2.85 & 1.81 & $\mathrm{U}=151.00$ & 0.460 \\
Shim & 6.82 & 3.54 & 5.79 & 2.30 & $\mathrm{U}=44.50$ & 0.352 \\
APQ & 5.06 & 2.97 & 4.23 & 1.62 & $\mathrm{U}=160.00$ & 0.636 \\
SAPQ & 7.74 & 6.33 & 6.30 & 1.87 & $\mathrm{U}=168.00$ & 0.813 \\
VAm & 22.88 & 10.55 & 17.89 & 7.70 & $\mathrm{U}=114.00$ & 0.067 \\
NHR & 0.17 & 0.06 & 0.16 & 0.05 & $\mathrm{U}=172.00$ & 0.906 \\
SPI & 11.45 & 4.89 & 15.12 & 5.90 & $\mathrm{t}=2.03$ & 0.049 \\
\hline M m & SD & &
\end{tabular}

M: mean; SD: standard deviation; t: result of t-test; U: result of Mann-Whitney test.

lesions and the controls) using a chi-square test, but no significant differences were found.

Laryngovideostroboscopy

In the study group, preoperative stroboscopic examination revealed sulcus vocalis or vergeture in 11 patients. In the remaining 5 cases, other laryngeal disorders were diagnosed (polyp in 2, nodules in 1, Reinke oedema in 2) and sulcus 
was only diagnosed during microlaryngoscopy (Figs. 2, 3). Data on glottal gap measurements are presented in Table V. We did not observe complete glottal closure in any patient in the study group, but it was present in $9 \%$ of individuals in the control group. The most frequent finding in the study group was irregular chink (56\%), whereas it was rarely seen in controls (5\%). The most characteristic shape of glottal closure in the control group was spindle glottic chink (68\%), which we observed in only $19 \%$ individuals in the study group.

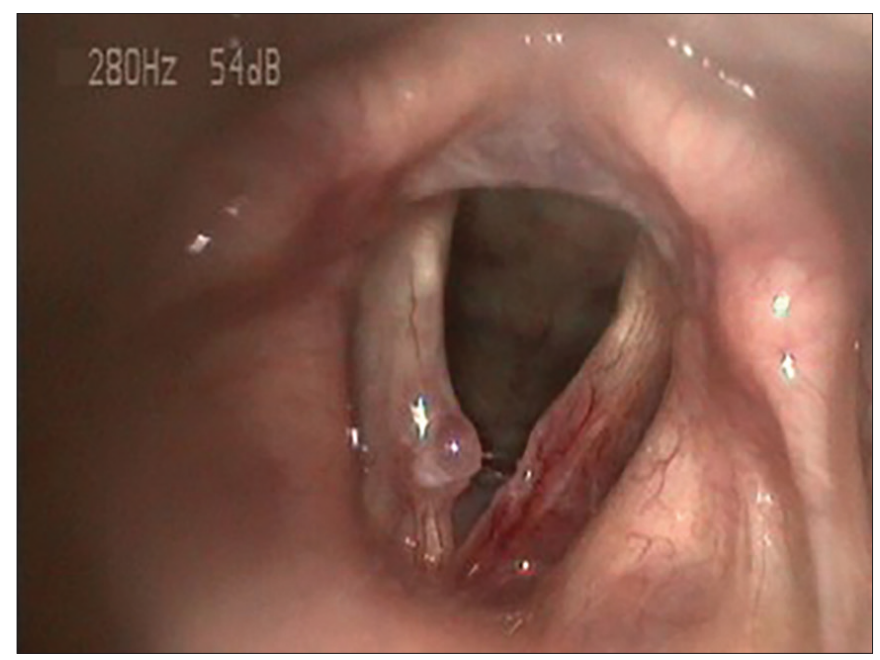

Figure 2. Laryngovideostroboscopy of a polyp on the right vocal fold and sulcus type 3 on the left vocal fold.

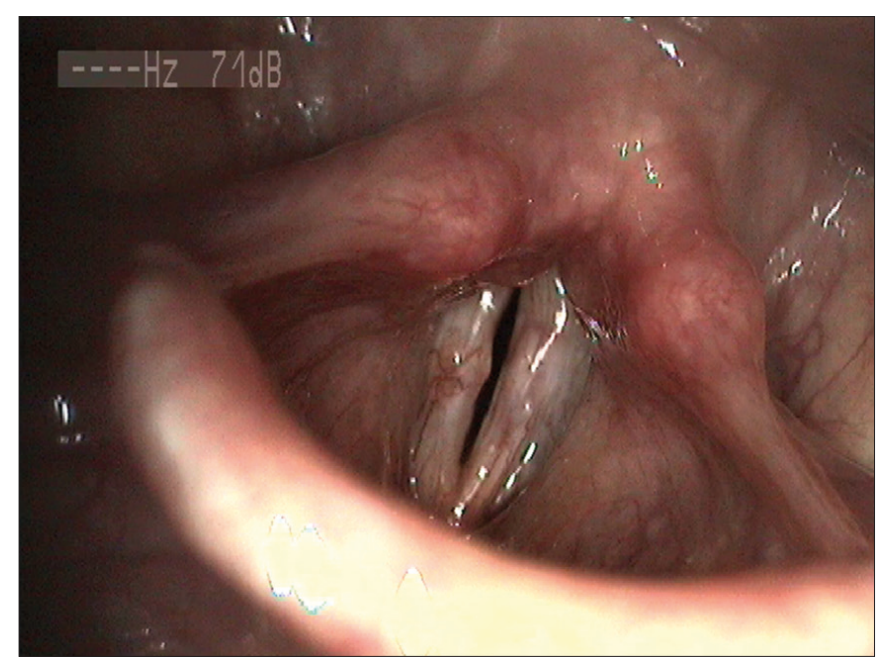

Figure 3. Laryngovideostroboscopy of bilateral sulcus type 3 and bilateral fibrous mass of the vocal folds.
In terms of glottal closure, significant differences between the groups were found $(\mathrm{p}=0.004)$.

In most patients in the study group the amplitude of vibration was diminished to a moderate degree (56\%); for $31 \%$ it was mild and severely diminished in $13 \%$. We did not note normal amplitude in any patient. The mucosal wave was moderately restricted in $75 \%$ of patients and severely in $25 \%$. We did not observe any patients with normal and mildly restricted mucosal wave.

The most frequent finding in the control group was moderately (46\%) and mildly (36\%) diminished amplitude; in $9 \%$ it was normal and severely diminished in $9 \%$. Regarding the mucosal wave it was moderately restricted in $64 \%$ individuals; in $18 \%$ it was mild and in $18 \%$ it was severely restricted. We did not find any subject with a normal mucosal wave.

Regarding comparison of the amplitude and the mucosal wave, there was no significant differences between groups ( $p>0.05$ ). In both groups the most frequent abnormal findings were moderately diminished amplitude and moderately restricted mucosal wave. Even though in the study group there were more patients with severely diminished amplitude (13\%) and severely restricted mucosal wave $(25 \%)$, the differences were not significant.

\section{Discussion}

Sulcus is not a rare vocal fold pathology, but it is difficult to diagnose. The heterogeneity in origin and clinical appearance makes the diagnosis and treatment of sulci a challenge ${ }^{5,13}$. This laryngeal condition frequently goes undetected and is only suspected after stroboscopic study. The presence of a concave medial edge of the vocal fold with glottal incompetence leads to the development of secondary hyperfunction and makes the vocal folds more susceptible to vocal abuse, which may predispose the patient to development of speech-trauma related lesions. In our cases, sulcus was associated with vocal fold fibrous mass, epidermoid cyst, mucosal bridge, polyp, nodules, and Reinke's oedema. According to the literature, sulcus may be detected or confirmed in approximately $30-40 \%$ of patients undergoing surgery for such lesions, thus confirming that sulcus is not easy to diagnose during stroboscopy ${ }^{8,12,23}$. Eckley and colleagues 9,23 . reported that the incidence of sulcus in those with polyps ranges from 22.2 to $36.4 \%$. Coexistence of a mucosal bridge and an epidermoid cyst,

Table V. Comparison of glottal closure in the study group ( $n=16)$ and control group ( $n=22)$.

\begin{tabular}{lccccccc} 
& Complete closure & Anterior chink & Posterior chink & Spindle shaped & Irregular & Incomplete closure \\
Study group & 0 & $1(6)$ & $1(6)$ & $3(19)$ & $9(56)$ & $2(13)$ & $\chi^{2}=17.22 ;$ \\
Control group & $2(9)$ & 0 & $2(9)$ & $15(68)$ & $1(5)$ & $2(9)$ & $p=0.004$ \\
\hline
\end{tabular}


in conjunction with sulcus vocalis, tends to reinforce a congenital origin, and indicates that these three lesions may represent different evolutionary stages ${ }^{1}$.

Structural vocal fold abnormalities in the sulcus lead to asymmetric vibrations and unbalanced muscular activity of the vocal folds ${ }^{23}$. Deformity of the vocal fold edge, abnormal glottis closure, irregular amplitude vibration and restricted mucosal wave seem to play a key role in the development of these benign lesions.

The most frequent finding in the study group was irregular chink $(56 \%)$, whereas in the controls it was spindle shaped closure (68\%). Intuitively, some coexisting lesions (i.e. nodules, polyp, oedema, cyst) may contribute to a reduction of glottal gap during phonation. Such a glottal configuration was also consistent with acoustic parameter Soft Phonation Index. The significantly lower values of SPI in patients with sulcus and coexistent lesions (in comparison to those with sulcus alone) may indicate that some concomitant lesions decrease the width of the glottal gap ${ }^{21}$.

The lack of complete glottal closure creates an air leak which reduces the patient's ability to produce a constant sound, leading to changes in vibratory amplitude that contribute to auditory-perceptual and acoustic measurements ${ }^{19}$. In the auditory-perceptual evaluation, the majority of patients in both groups had a mild grade of hoarseness, roughness, or breathiness as well as an asthenic or strained voice quality, which is consistent with other reports ${ }^{24,25}$. The only exception was that moderate roughness was observed in most subjects in the control group.

In objective acoustic assessments, the most abnormally increased values were amplitude parameters. Peak-to-peak vibratory amplitudes (vAm) were higher in cases of sulcus with concomitant lesions (although the difference was not statistically significant in comparison to sulcus alone). The mean values of frequency parameters were slightly elevated. The lack of significant differences between groups, except for SPI, suggests that acoustic structure of the voice in both series of patients was determined by the presence of sulcus. Many authors report a large discrepancy between acoustic measurements and VHI-30 ${ }^{26,27}$. As in other reports, the VHI-30 scores in the study group were influenced by gender allocation ${ }^{15}$. The control group had an even sex distribution, whereas in the study group there was a prevalence of women, in contrast with the literature ${ }^{24,28,29}$. Patients with sulcus and concomitant benign lesions had significantly higher emotional and functional VHI-30 scores. The high score on the emotional subscale may stem from a clear prevalence of women in our study group since vocal nodules, cyst, or Reinke's oedema are more common in females ${ }^{30}$. Despite the lack of statistical significance $(p=0.050)$ between the groups, the total VHI score was higher in the study group. Welham et al. ${ }^{3}$ reported similar observations in a group with sulcus and concomitant scar/ oedema. This suggests that sulcus with coexisting lesions is more handicapping than is sulcus alone.

Our study design has some limitations and the data should be interpreted carefully. Importantly, only 16 patients with sulcus and concomitant lesions were included in the study group. This is a small sample, especially considering the heterogeneity in clinical presentation. We gathered subjects with two types of sulcus (types 2 and 3) with different concomitant laryngeal disorders afflicting one or both vocal folds. Our findings reflect the clinical complexity of these patients, but the small number also limits direct comparison between the study and control groups. It is worth noting the inhomogeneity in gender between the two groups.

\section{Conclusions}

The clinical characteristics indicate that the presence of sulcus primarily determines the quality of voice, and that the additional benign pathologies do not drastically affect further voice deterioration. The coexistence of secondary benign vocal fold lesions aggravates the difficulties in making a preoperative diagnosis of sulcus. Therefore, it is important to clinically suspect the possibility of coexistent sulcus to individualise treatment, including surgery, to obtain better voice outcomes and decrease the chance of recurrence of benign lesions involving the vocal fold.

\section{References}

1 Bouchayer M, Cornut G. Microsurgical treatment of benign vocal fold lesions: indications, technique, results. Folia Phoniatr 1992;44:15584. https://doi.org/10.1159/000266150

2 Ford CN, Inagi K, Bless DM, et al. Sulcus vocalis: a rational analytical approach to diagnosis and management. Ann Otol Rhinol Laryngol 1990;105:189-200. https://doi.org/10.1177/000348949610500304

3 Welham NV, Dailey SH, Ford CN, et al. Voice handicap evaluation of patients with pathologic sulcus vocalis. Ann Otol Rhinol Laryngol 2007;116:411-7. https://doi.org/10.1177/000348940711600604

4 Lee A, Sulica L, Aylward A, et al. Sulcus vocalis; a new clinical paradigm based on a reevaluation of histology. Laryngoscope 2016;126:1397-403. https://doi.org/10.1002/lary.25732

5 Giovanni A, Chanteret C, Lagier A. Sulcus vocalis: a review. Eur Arch Otorhinolaryngol 2007;264:337-44. https://doi.org/10.1007/s00405006-0230-8

6 Welham NV, Choi SH, Dailey SH, et al. Prospective multi-arm evaluation of surgical treatment for vocal fold scar and pathologic sulcus vocalis. Laryngoscope 2011;121:2152-60. https://doi.org/10.1002/lary.21780

7 Nakayama M, Ford CN, Brandenburg JH, et al. Sulcus vocalis in laryngeal cancer: a histopathologic study. Laryngoscope 1994;104:1624. https://doi.org/10.1288/00005537-199401000-00005

8 Itoh T, Kawasaki H, Morikawa I, et al. Vocal fold furrows. A 10-year review of 240 patients. Auris Nasus Larynx 1983;10:17-26. https:// doi.org/10.1016/S0385-8146(83)80002-9

9 Remacle M, Lawson G, Evrard I, et al. Microsurgery of sulcus vergeture 
with carbon dioxide laser and injectable collagen. Ann Otol Rhinol Laryngol 2000;109:141-8. https://doi.org/10.1177/000348940010900206

10 Eckley CA, Swensson J, de Campos Duprat A, et al. Incidence of structural vocal fold abnormalities associated with vocal fold polyps. Rev Bras Otorhinolaringol 2008;74:508-11. https://doi.org/10.1590/ S0034-72992008000400005

11 Martins RH, Santana M, Tavares EL. Vocal cysts: clinical, endoscopic, and surgical aspects. J Voice 2011;25:107-10. https://doi. org/10.1016/j.jvoice.2009.06.008

12 Byeon HK, Kim JH, Kwon JH, et al. Clinical characteristics of vocal polyps with underlying sulcus vocalis. J Voice 2013;27:632-5. https:// doi.org/10.1016/j.jvoice.2013.04.010

13 Miaśkiewicz B, Szkiełkowska A. Diagnostic difficulties in sulcus vocalis. Now Audiofonol 2015;4:60-3. https://doi.org/10.1007/s00405018-5040-2

14 Carmel-Niederman N, Wasserzug O, Ziv-Baran T, et al. Coexisting vocal fold polyps and sulcus vocalis:coincidence or coexistence? Characteristics of 14 patients. J Voice 2017;32:239-43. https://doi. org/10.1016/j.jvoice.2017.04.006

15 Jacobson B, Johnson A, Grywalski C, et al. The Voice Handicap Index (VHI): development and validation. Am J Speech Lang Pathol 1997;6:66-9. https://doi.org/10.1044/1058-0360.0603.66

16 Hirano M. Psycho-acoustic evaluation of voice. In: Arnold GE, Winckel F, Wyke BD, editors. Clinical examination of voice. New York: Springer-Verlag; 1981. pp. 81-4.

17 Revis J, Giovanni A, Wuyts FL, et al. Comparison of different voice samples for perceptual analysis. Folia Phoniatr Logop 1999;51:10816. https://doi.org/10.1159/000021485

18 Schindler A, Mozzanica F, Vedrody M, et al. Correlation between the Voice Handicap Index and voice measurements in four groups of patients with dysphonia. Otolaryngol Head Neck Surg 2009;141:7629. https://doi.org/10.1016/j.otohns.2009.08.021

19 Nicastri M, Chiarella G, Gallo LV, et al. Multidimensional Voice Program (MDVP) and amplitude variation parameters in euphonic adult subjects. Normative study. Acta Otorhinolaryngol Ital 2004;24:337-41.
20 Deliyski DD. Acoustic model and the evaluation of pathological voice production. Proceedings: $3^{\text {rd }}$ Conference on Speech Communication and Technology Eurospeech 1993, Berlin, Germany, pp. 1969-72.

21 Kay Elemetrics Corp. Software instruction manual. Multi-Speech and CSL Software. Lincoln Park, USA: Kay Elemetrics; 2004.

22 Lim JY, Kim J, Choi SH, et al. Sulcus configurations of vocal folds during phonation. Acta Oto-Laryngol 2009;129:1127-35. https://doi. org/10.1080/00016480802579058

23 Bouchayer M, Cornut G, Loire R, et al. Epidermoid cyst, sulci, and mucosal bridges of the true vocal cord: a report of 157 cases. Laryngoscope 1985;95:1087-94.

24 Eckley CA, Corvo MA, Yoshimi R, et al. Unsuspected intraoperative finding of structural abnormalities associated with vocal fold polyps. J Voice 2010;24:623-5. https://doi.org/10.1016/j.jvoice.2009.02.001

25 Hirano M, Yoshida T, Tanaka S, et al. Sulcus vocalis: functional aspects. Ann Otol Rhinol Laryngol 1990;99:679-83. https://doi. org/10.1177/000348949009900901

26 Hsiung MW, Pai L, Wang HW. Correlation of Voice Handicap Index and voice laboratory measurements in dysphonic patients. Eur Arch Otorhinolaryngol 2002;259:97-9. https://doi.org/10.1007/ s004050100405

27 Wheeler KM, Collins SP, Sapienza CM. The relationship between VHI scores and specific acoustic measures of mildly disordered voice production. J Voice 2006;20:308-17. https://doi.org/10.1016/j. jvoice.2005.03.006

28 Sunter AV, Yigit O, Huq GE, et al. Histopathological characteristics of sulcus vocalis. Otolarngol Head Neck Surg 2011;145:264-9. https:// doi.org/10.1177/0194599811404639

29 Selleck AM, Moore JE, Rutt AL, et al. Sulcus vocalis (type III): prevalence and strobovideolaryngoscopy characteristics. J Voice 2015;29:507-11. https://doi.org/10.1016/j.jvoice.2014.09.015

30 Zhukhovitskaya A, Battaglia D, Khosla SM, et al. Gender and age in benign vocal fold lesions. Laryngoscope 2015;125:191-6. https://doi. org/10.1002/lary.24911 